Trial Design

\title{
Rationale and Design of the ICON-RELOADED Study: International Collaborative of N- terminal pro-B-type Natriuretic Peptide Re-evaluation of Acute Diagnostic Cut-Offs in the Emergency Department
}

\author{
Brief Title (45 characters): ICON-RELOADED Study Design and Rationale
}

Gaggin HK, MD, MPH*广‡; Chen-Tournoux AA, MD ${ }^{\S}$; Christenson RH, $\mathrm{PhD}^{\prime}$; Doros G, $\mathrm{PhD}^{\ddagger \neq}$; Hollander JE, MD ${ }^{\text {If }}$ Levy PD, MD*; Nagurney JT, MD*广; Nowak RM, MD**; Pang PS, MD, $\mathrm{MS}^{\dagger \dagger}$; Patel D, MS ${ }^{\ddagger \ddagger}$; Peacock WF, MD ${ }^{\S \S}$; Walters EL, MD"; and Januzzi JL, MD ${ }^{* \dagger \neq}$ on behalf of the ICON-RELOADED Investigators.

* Massachusetts General Hospital, Boston, MA, USA

${ }^{\dagger}$ Harvard Medical School, Boston, MA, USA

${ }^{\ddagger}$ Baim Institute for Clinical Research, Boston, MA, USA

${ }^{\S}$ Jewish General Hospital, Montreal, PQ, Canada

'University of Maryland School of Medicine, Baltimore, MD, USA

${ }^{7}$ Department of Biostatistics, Boston University, MA, USA

"IJefferson University, Philadelphia, PA, USA

\#Wayne State University, Detroit, MI, USA

**Henry Ford Health System, Detroit, MI, USA

†IIndiana University School of Medicine \& Indianapolis EMS, Indianapolis, IN, USA

${ }^{\ddagger \ddagger}$ Roche Diagnostics, Indianapolis, IN, USA

${ }_{\S \S}$ Baylor College of Medicine, Houston, TX, USA

"Loma Linda University Medical Center, Loma Linda, CA, USA

Address for Correspondence:

James L. Januzzi, Jr, MD, FACC, FESC

Massachusetts General Hospital

Yawkey 5B, Boston, MA, 02114

P: 617-726-3443, F: 617-643-1620

JJanuzzi@mgh.harvard.edu

Funded by Roche Diagnostics, Inc.

Word Count: 4124 words.

\section{Conflicts of Interest}

Dr. Gaggin has received grant support from Roche Diagnostics and Portola; consulting income from Roche Diagnostics, Amgen, Boston Heart Diagnostics and Ortho Clinical; research payments for clinical endpoint committees for EchoSense and Radiometer. Dr. Chen-Tournoux has received consulting income from Roche Diagnostics. Dr. Christenson has received support from Roche Diagnostics, Siemens Healthcare Diagnostics, Beckman Coulter, Spingotech, Ortho 
Clinical Diagnostics, and Abbott. Dr. Doros has received consulting income from Pfizer, Genzyme, and Sarepta. Dr. Hollander has received support from PCORI, NIH, Alere, Siemens, Roche, Portola, and Trinity. Dr. Levy has received support from PCORI, NIH, Siemens, Roche, Thermofisher, Amgen, Novartis, Trevena, Cardiorentis, and ZS Pharma. Dr. Nagurney has received grant support from Roche Diagnostics, Alere/Biosite, Boehringer Ingelheim, Thermo Fisher and Nanosphere. Dr. Nowak receives grant support from Roche Diagnostics, Siemens, Abbott, Novartis, and Radiometer, and is a consultant for Roche, Siemens, Abbott, Trinity, and Thermofisher. Dr. Pang is or has been in the past one year a consultant for BMS, Novartis, Trevena, scPharmaceuticals, Roche Diagnostics, and Relypsa, and has received research support from Roche, Novartis, PCORI, IUSM, Indianapolis EMS. Ms. Patel was an employee of Roche Diagnostics. Dr. Peacock has received grants support from Abbott, Alere, Banyan, Cardiorentis, Janssen, Pfizer, Roche, The Medicine's Company, ZS Pharma; has served as a consultant for Alere, Cardiorentis, Ischemia Care, Janssen, Phillips, Prevencio, The Medicine's Company, ZS Pharma; and has ownership interests in Comprehensive Research Associates LLC, and Emergencies in Medicine LLC. Dr. Walters received investigator funding for this study from Roche Diagnostics. Dr. Januzzi has received grant support from Siemens, Singulex and Prevencio; consulting income from Roche Diagnostics, Critical Diagnostics, Sphingotec, Phillips, and Novartis; and participates in clinical endpoint committees/data safety monitoring boards for Novartis, Amgen, Janssen, and Boehringer Ingelheim. 


\section{ABSTRACT:}

Objectives: To re-assess use of amino-terminal pro B-type natriuretic peptide (NT-proBNP) concentrations for diagnosis and prognosis of acute heart failure (HF) in patients with acute dyspnea.

Background: NT-proBNP facilitates diagnosis, prognosis, and treatment in patients with suspected or proven acute HF. As demographics of such patients are changing, previous diagnostic NT-proBNP thresholds may need updating. Additionally, value of in-hospital NTproBNP prognostic monitoring for HF is less understood.

Methods: In a prospective, multicenter study in the United States and Canada, patients presenting to emergency departments with acute dyspnea were enrolled, with demographic, medication, imaging and clinical course information collected. NT-proBNP analysis will be performed using the Roche Diagnostics Elecsys ${ }^{\circledR}$ proBNPII immunoassay in blood samples obtained at baseline and at discharge (if hospitalized). Primary endpoints include positive predictive value (PPV) of previously established age-stratified NT-proBNP thresholds for the adjudicated diagnosis of acute HF, and its negative predictive value (NPV) to exclude acute HF. Secondary endpoints include sensitivity, specificity, and positive and negative likelihood ratios for acute HF and among those with HF the prognostic value of baseline and pre-discharge NTproBNP for adjudicated clinical endpoints (including all-cause death and hospitalization) at 30 and 180 days.

Results: 1461 dyspneic subjects have been enrolled and are eligible for analysis. Follow-up for clinical outcome is ongoing.

Conclusions: The International Collaborative of N-terminal pro-B-type Natriuretic Peptide Reevaluation of Acute Diagnostic Cut-Offs in the Emergency Department study offers a contemporary opportunity to understand best diagnostic cutoff points for NT-proBNP in acute $\mathrm{HF}$, and validate in-hospital monitoring of HF using NT-proBNP. 


\section{KEY WORDS:}

NT-proBNP

Acute heart failure

Biomarker

Diagnosis

Prognosis

\section{ABBREVIATIONS:}

CI: confidence interval

ED: emergency department

HF: heart failure

HFpEF: heart failure with preserved ejection fraction

HFrEF: heart failure with reduced ejection fraction

ICON: International Collaborative of NT pro-BNP

LR-: negative likelihood ratio

LR+: positive likelihood ratio

NT-proBNP: N-terminal pro B-type natriuretic peptide

NPV: negative predictive value

PPV: positive predictive value

PRIDE: N-Terminal Pro-BNP Investigation of Dyspnea in the Emergency Department 
Acute heart failure (HF) can be challenging to diagnose, as symptoms and signs often overlap with other conditions, leading to both under and over recognition, and incorrect treatment. Testing of blood for the presence of natriuretic peptides facilitates the diagnosis, as well as provides an objective indication of the severity and prognosis, of HF. B-type natriuretic peptide (BNP), and its amino-terminal pro-peptide cleavage equivalent, NT-proBNP, are both sensitive and specific biomarkers for the diagnosis of acute HF (1-4). In prospective, randomized clinical trials of patients presenting with symptoms of acute dyspnea, natriuretic peptides improved clinician diagnostic accuracy for acute $\mathrm{HF},(5)$ reduced health care expenditures, and improved outcomes compared with clinical judgment alone.(6)

Though embedded as a Class I Level of Evidence A in clinical practice guidelines for diagnostic evaluation of $\mathrm{HF}$ (7), questions remain regarding the current use of natriuretic peptides. In the past few decades, considerable changes in HF demographics have occurred. Patients with HF are generally older, with more co-morbidities such as atrial fibrillation, anemia, and chronic kidney disease;(8) all of these differences may cause higher than expected natriuretic peptide concentrations.(9) Drugs for HF (i.e., sacubitril/valsartan), which directly raise BNP concentrations and simultaneously lower NT-proBNP, are now available. Conversely, compared to earlier decades, there is increasing incidence and prevalence of HF with preserved ejection fraction $(\mathrm{HFpEF})$ and patients are generally more obese, $(10,11)$ both of which may cause lowerthan-expected natriuretic peptide concentrations. $(12,13)$ Accordingly, presently utilized diagnostic thresholds for natriuretic peptides may require a re-assessment.

For NT-proBNP, historical regulatory-approved thresholds were based on data generated from testing in non-acute patients, a population different from typical patients encountered in the emergency department (ED); Moreover, these cutoffs were developed for their high negative predictive value (NPV), with the intent of excluding HF, rather than for their positive predictive value (PPV) in identifying HF. While NPV is of value, identification of PPV-optimized cut-offs is important as well. In this regard, the N-Terminal Pro-BNP Investigation of Dyspnea in the Emergency Department (PRIDE) and International Collaborative of NT-proBNP (ICON) studies identified PPV-optimized cut-offs for the identification of acute HF. In these studies, an approach of using diagnostic thresholds of $450 \mathrm{pg} / \mathrm{mL}, 900 \mathrm{pg} / \mathrm{mL}$ and $1800 \mathrm{pg} / \mathrm{mL}$ for age categories of $<50,50-75$ and $>75$ years, respectively, was considerably more accurate, improving specificity without sacrificing sensitivity(14). While both the age-stratified NTproBNP approach and the NPV-optimized cut off of $300 \mathrm{pg} / \mathrm{mL}$ to exclude acute HF has been endorsed by clinical practice guidelines (7), consensus statements, (15) and top-tier research journal summaries (16), regulatory-approved thresholds for NT-proBNP remain unchanged for use in acute dyspnea, leading to considerable confusion. Thus, opportunities exists not only to validate age-stratified cut-points for NT-proBNP, but to do so in a more contemporary cohort.

Beyond diagnosis, NT-proBNP also facilitates assessment of HF severity as well as the prediction of prognosis in patients with acute $\operatorname{HF}(14,17,18)$. While concentrations of NTproBNP at presentation with acute $\mathrm{HF}$ are strongly prognostic, post-treatment concentrations are 
even more powerfully predictive of hospitalization or death; accordingly, recent enthusiasm has grown in use of NT-proBNP for prognostic monitoring during hospital treatment for acute HF. However, although retrospective data suggest in-hospital change in NT-proBNP may be useful for prognosis,(19-23), prospectively collected data are limited.

Accordingly, the primary aim of this study is to validate the ICON cut-offs in a contemporary cohort. Additionally, as a secondary aim, this study will prospectively evaluate the value of inhospital NT-proBNP monitoring for prediction of clinical outcomes. The design, population, endpoints, and statistical considerations for the International Collaborative of N-terminal pro-Btype Natriuretic Peptide Re-evaluation of Acute Diagnostic Cut-Offs in the Emergency Department (ICON-RELOADED) Study are described.

\section{METHODS}

The institutional review board at each participating institution approved the study, and all patients provided written informed consent prior to enrollment. Funding was provided by Roche Diagnostics. Joanna Suomi, MSc, contributed to the writing and editing of this manuscript as an employee of the Baim Institute for Clinical Research.

\section{Study Design, Setting, and Evaluations}

The ICON-RELOADED Study is a prospective, multicenter clinical trial conducted at 19 sites in the United States and Canada (Figure 1). 


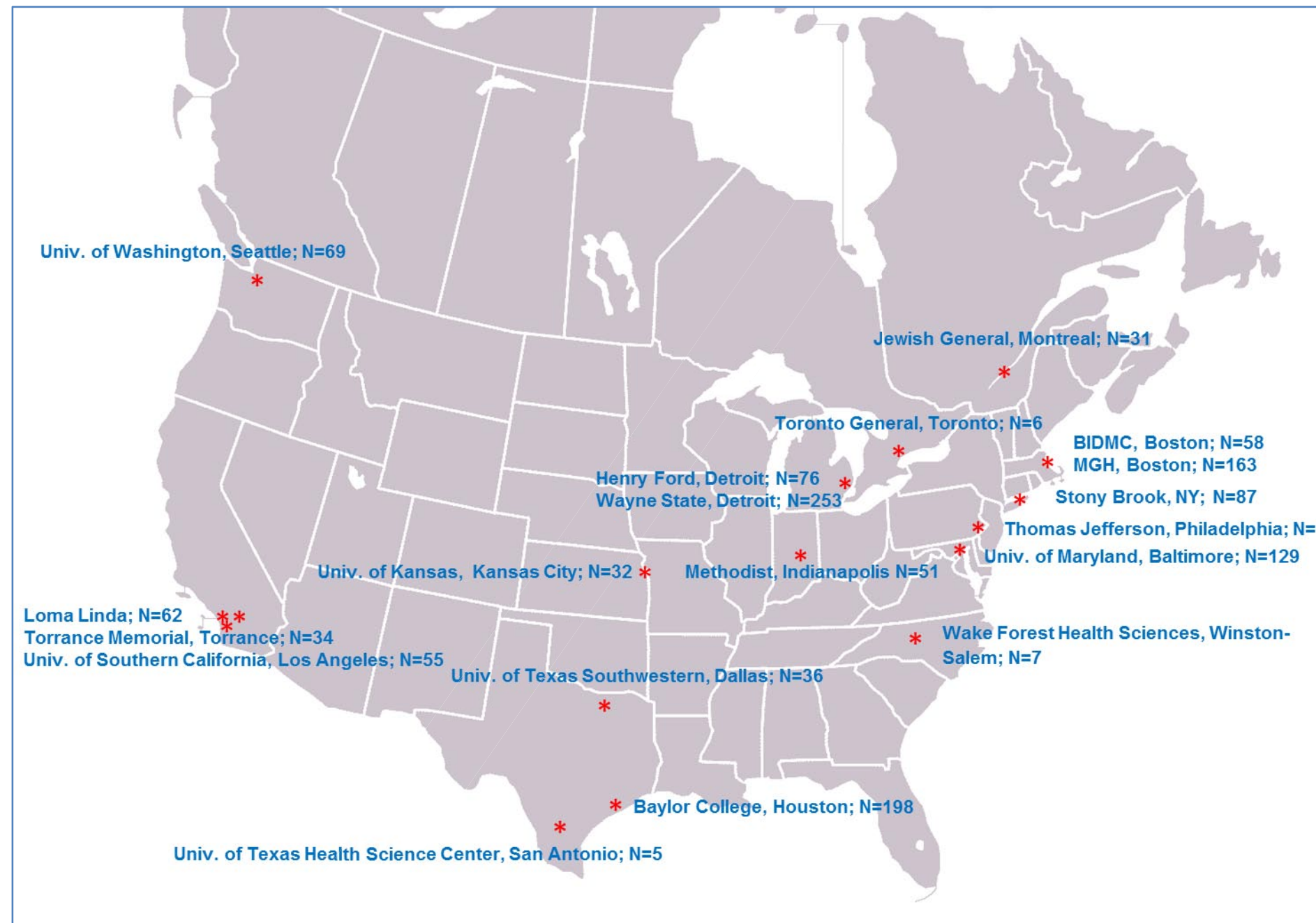

Figure 1: Study site distribution. A wide range of sites enrolled 1461 patients and provided a balanced demographic of patients.

Abbreviations: BIDMC, Beth Israel Deaconess Medical Center; MGH, Massachusetts General Hospital.

A total of 1461 patients presenting to ED with acute dyspnea were enrolled between October 2015 and October 2016. As seen in Table 1, blood samples were collected at enrollment and at hospital discharge (unless the patient was discharged from the emergency department). Post discharge clinical events were obtained at 180 days ( \pm 14 days) via phone call with patient or primary care physician when needed.

Table 1. ICON-RELOADED timeline.

\begin{tabular}{|l|c|c|c|}
\hline & $\begin{array}{c}\text { Evaluations at } \\
\text { Enrollment }\end{array}$ & $\begin{array}{c}\text { Evaluations at } \\
\text { Discharge }\end{array}$ & $\begin{array}{c}\text { Evaluations at } \\
\mathbf{1 8 0} \pm 14 \text { Days }\end{array}$ \\
\hline & Oct 2015- Oct 2016 & $\begin{array}{c}\text { Apr 2016- } \\
\text { Apr 2017 }\end{array}$ \\
\hline
\end{tabular}




\begin{tabular}{|l|c|c|c|}
\hline & \multicolumn{2}{|c|}{} \\
\hline NT-proBNP and biorepository blood samples & $\mathrm{X}$ & $\mathrm{X}^{*}$ & \\
\hline DNA sample** & $\mathrm{X}$ & & \\
\hline Clinical course & $\mathrm{X}$ & $\mathrm{X}$ & $\mathrm{X}$ \\
\hline Concomitant medications & $\mathrm{X}$ & $\mathrm{X}$ & $\mathrm{X}$ \\
\hline Adverse events & $\mathrm{X}$ & $\mathrm{X}$ & $\mathrm{X}$ \\
\hline
\end{tabular}

*If patients were discharged from ED directly home, no discharge sample had to be collected. There may have been an additional pre-discharge blood draw if the subject remained in hospital for more than 24 hours since the previous pre-discharge blood draw.

** To be drawn from those that consented to this procedure.

\section{Study Objectives}

The primary objective of this study is to externally validate the use of Elecsys ${ }^{\circledR}$ proBNP (Roche Diagnostics, Indianapolis, IN, USA) concentrations to aid in the diagnosis of HF in patients presenting emergently through use of the ICON cut-point strategy(14). This will identify ("rule in") or exclude ("rule out") the diagnosis of acute HF (Table 2).

Table 2: Proposed NT-proBNP cut-points for diagnosis or exclusion of acute heart failure. Based on earlier studies, these thresholds will be re-evaluated in the ICON-RELOADED Study.

\begin{tabular}{|l|c|}
\hline Threshold for Diagnosis of Acute HF & Patient Age Group \\
\hline $450 \mathrm{pg} / \mathrm{mL}$ & $<50$ years \\
\hline $900 \mathrm{pg} / \mathrm{mL}$ & $50-75$ years \\
\hline $1800 \mathrm{pg} / \mathrm{mL}$ & $\geq 75$ years \\
\hline Threshold for Exclusion of Acute HF & Patient Age Group \\
\hline $300 \mathrm{pg} / \mathrm{mL}$ & N/A \\
\hline
\end{tabular}

As a secondary aim, we will determine the value of in-hospital change of NT-proBNP relative to other clinical and biochemical variables predicting post-discharge outcomes.

\section{Study Population}

Patients presenting to emergency departments with acute dyspnea were enrolled if they met all of the inclusion criteria and had no exclusion criteria, as listed in Table 3. 
Table 3. Patient eligibility criteria. A patient had to meet all of the listed inclusion criteria to participate in the study. A patient was excluded from participation if s/he met any of the clinical exclusion criteria, and a sample was excluded from the study if it met any of the sample exclusion criteria.

\begin{tabular}{|l|l|}
$\begin{array}{l}\text { Enrollment } \\
\text { Inclusion } \\
\text { Criteria }\end{array}$ & $\begin{array}{l}\text { Age } \geq 22 \text { years } \\
\text { Admission to the emergency department with acute dyspnea } \\
\text { Written informed consent }\end{array}$ \\
\hline $\begin{array}{l}\text { Clinical } \\
\text { Criteria }\end{array}$ & $\begin{array}{l}\text { Renal insufficiency requiring dialysis or known estimated glomerular filtration rate <15 } \\
\mathrm{mL} / \mathrm{min} / 1.73 \mathrm{~m}^{2} \text { prior to enrollment } \\
\text { Dyspnea after chest trauma } \\
\text { Subject unable to donate up to 50 mL of blood at one time }\end{array}$ \\
$\begin{array}{l}\text { Known pregnancy } \\
\text { Unreliable or non-compliant, including patients with known history of active alcoholism, } \\
\text { drug abuse, or serious psychiatric disorder that may lead to noncompliance; as well as } \\
\text { patients unwilling to abide by the requirements of the protocol } \\
\text { Any known conditions (e.g. psychiatric history, language barrier, absence of legal } \\
\text { representative, etc.) that would interfere with the patient's ability to comply with study } \\
\text { instructions, might confound the interpretation of the study, or put the patient at risk } \\
\text { Personnel, or any relative of personnel of the Sponsor, the Contract Research Organization, } \\
\text { or the investigative site(s) }\end{array}$ \\
$\begin{array}{l}\text { Sample } \\
\text { Exclusion } \\
\text { Criteria }\end{array}$ & $\begin{array}{l}\text { Visible hemolysis, lipemia or icterus } \\
\text { Known interferents with NT-proBNP assay such as high dose biotin use. } \\
\text { Visible particulates } \\
\text { Insufficient quantity } \\
\text { Specimens not collected, handled, stored or shipped properly }\end{array}$ \\
\hline
\end{tabular}

\section{Biorepository}

Fifty (50) mL of blood was collected from each patient enrolled using serum, Lithium-Heparin (Li-Hep) Plasma, and ethylene-diamineteraacetic acid (EDTA) tubes, with DNA extraction performed from the EDTA tube. Serum tubes sat at room temperature to allow the clot to form. Plasma tubes were immediately stored at $2-8^{\circ} \mathrm{C}$ prior to centrifugation. A subject that did not have at least 8,0.30 $\mathrm{mL}$ aliquots from the Li-Hep Plasma tube was designated as a "dropped" subject for enrollment status. If less than $8,0.30 \mathrm{~mL}$ aliquots were obtained from the EDTA tubes, the subject was not "dropped" as the primary matrix of interest for regulatory approval will be Li-Hep; the EDTA samples will be utilized for creation of a biorepository for assessing novel HF markers of interest while cross-validating quality performance NT-proBNP assays in 
different matrices. Samples were stored at $-70^{\circ} \mathrm{C}$ or colder, and shipped to the ICONRELOADED Biorepository.

For discharge blood samples, $50 \mathrm{~mL}$ of blood was collected, also the same protocol, within 24 hours of planned discharge.

Samples will be maintained in the ICON-RELOADED Biorepository until the time of NTproBNP testing ( $<1$ year), which will be performed using the commercially available Elecsys proBNP II (Roche Diagnostics, Indianapolis, IN) immunoassay, according to established methods.

\section{Study Endpoints}

\section{Primary Efficacy Endpoints}

The primary efficacy endpoints for this study are the positive predictive value (PPV) of agespecific rule-in thresholds of $450 / 900 / 1800 \mathrm{pg} / \mathrm{mL}$ for ages $<50 / 50-75 / \geq 75$ years for the diagnosis of acute HF, and the negative predictive value (NPV) of the rule-out threshold of 300 $\mathrm{pg} / \mathrm{mL}$ to exclude the adjudicated diagnosis of acute $\mathrm{HF}$.

\section{Secondary Efficacy Endpoints.}

Secondary endpoints include the NPV, positive likelihood ratio (LR+), negative likelihood ratio (LR-), sensitivity and specificity for the age-specific rule-in thresholds as well as the PPV, LR+, LR-, sensitivity and the specificity for the rule-out threshold.

In addition, all efficacy endpoints will be evaluated by region (United States and Canada) for regulatory purposes.

\section{Secondary Clinical Endpoints}

We will assess the following clinical outcomes at 30- and 180-days post discharge: major adverse cardiac events following index presentation or hospitalization (MACE, a composite of all-cause death or HF hospitalization), all-cause death, cardiac death, all-cause hospitalization and HF hospitalization. Using baseline and discharge characteristics as well as NT-proBNP concentrations at baseline and discharge, we will develop a multivariable model for the prediction of clinical outcomes.

\section{Statistical Considerations}

\section{Sample Size Calculation}

The study was designed to include 1765 patients to ensure a sample of at least 1500 analyzable patients, accounting for an assumed attrition rate of approximately $15 \%$. A maximum of $15 \%$ of patients were to be enrolled from sites in Canada, thereby intending 1500 enrolled and 1275 
analyzable patients from the United States, and 265 enrolled and 225 analyzable patients from Canada.

\section{Statistical Analyses}

\section{Efficacy Endpoints}

Operating characteristics of the proposed age-based thresholds combined (for rule-in) and the proposed threshold for rule-out relative to the gold-standard diagnosis will be evaluated, including sensitivity, specificity, PPV, NPV, LR+ and LR-. Estimates and CIs for the NPV and PPV parameters will be determined.(24) Estimates, CIs and tests for the likelihood ratios parameters, LR+ and LR-, will be carried out using a non-linear mixed effects model. Based on data generated in the ICON study,(14) overall sensitivity and specificity of the proposed agedependent thresholds are expected to be $90.0 \%$ and $84.0 \%$, respectively. The expected PPV is $85.0 \%$ and the $\mathrm{LR}+$ is estimated at 5.62 .

With a planned sample size of 1,500 analyzable patients and an assumed prevalence of HF of $50 \%$ in this population,(14) the lower bound of a 95\% two-sided CI for the hypothesized PPV is $82.6 \%$ while for lower bound for the hypothesized LR+ is expected to be 4.77 , which would establish the proposed test as a useful tool to aid diagnosis of acute HF in this population.(25) A planned sample of 1,275 analyzable patients from the United States would result in lower bounds of a two-sided $95 \% \mathrm{CI}$ for the PPV of $82.5 \%$ and for LR+ of 4.6, therefore providing substantial precision.

With a proposed rule-out threshold of $300 \mathrm{pg} / \mathrm{mL}$, the expected sensitivity and specificity values are $99.0 \%$ and $60.0 \%$, respectively.(14) Thus, the expected NPV is $98.5 \%$ and the LR- is 0.017 , with a lower bound for a two-sided $95 \%$ CI for the NPV of $96.7 \%$ and a upper bound for a twosided $95 \%$ CI of 0.034 , thereby establishing the proposed test as a useful tool in the aid of excluding acute $\mathrm{HF}$ in this population.(25)

\section{Clinical Endpoints}

Univariable comparison of baseline and discharge characteristics (NT-proBNP concentrations, as below) between patients with and without a composite endpoint of all-cause death or repeat HF hospitalization will be assessed at 30 and 180 days post discharge using $\chi^{2}$ test for categorical variables and Mann-Whitney for continuous variables. Normally distributed variables are presented as mean \pm standard deviation and non-normally distributed variables are shown as median with interquartile range. Age, sex and other variables that are statistically significant will be considered as a candidate variable in a multivariable prediction of the time-to composite endpoint with a retention value of $\mathrm{p}>0.1$ in a Cox proportional hazard model. Co-linearity will be assessed and non-parametric continuous variables will be transformed to fit a normal curve. Concentrations of NT-proBNP will be assessed as absolute values at baseline and discharge as well as change from baseline to discharge (absolute difference as well as relative percent change 
from baseline value). A responder will be defined as relative percent difference in NT-proBNP from baseline to discharge $\geq 30 \%$ and a non-responder will be defined as NT-proBNP change $<30 \%$. In addition, multivariable prediction models for re-hospitalization will be performed using multivariable logistic regression.

\section{Diagnostic Subgroups of Interest}

As it is well-known that NT-proBNP may be influenced by certain important medical comorbidities, diagnostic subgroups of interest have been pre-specified. These include (1) HF with reduced $\mathrm{EF}$ (HFrEF) versus HFpEF (defined as left ventricular EF <50\% vs. $\geq 50 \%$ ); (2) sex; (3) race (black vs. non-black); (4) obesity (body mass index <30.0 vs. $\geq 30.0 \mathrm{~kg} / \mathrm{m}^{2}$ ); (5) with or without a history of atrial fibrillation; and (6) with or without renal insufficiency (eGFR $\leq 60.0$ $\mathrm{mL} / \mathrm{min} / 1.73 \mathrm{~m}^{2}$ vs. eGFR $>60.0 \mathrm{~mL} / \mathrm{min} / 1.73 \mathrm{~m}^{2}$ ). Because decompensation of chronic $\mathrm{HF}$ is a very important predictor of the diagnosis of acute HF, we will evaluate discrimination and operating characteristics of NT-proBNP in patients with acute on chronic as well as de novo HF.

\section{Clinical Event Adjudication}

The Clinical Events Committee (CEC) includes a panel of physicians (cardiologists and emergency physicians) who are independent from the study. CEC meetings will include a minimum of 2 emergency physicians and 1 cardiologist or interventional cardiologist for the adjudication of pre-specified clinical endpoints based on charter-based criteria used for the categorization of clinical events in the study (see Appendix for definitions).

\section{Assessment of $\mathrm{HF}$}

For the assessment of HF diagnosis, the members of the CEC will be blinded to local site NTproBNP or BNP concentrations during index hospitalization, if performed for standard of care. Adjudication will be performed prior to the performance of central laboratory NT-proBNP testing for regulatory submission. The CEC will adjudicate the diagnosis for each patient at presentation, categorized as acute HF, acute HF and additional active diagnosis (e.g., pulmonary, other cardiac, anemia), other diagnosis and no HF (incident or prevalent), or other diagnosis and prior background of HF without acute decompensation.

\section{Endpoint Assessment}

For assessment of clinical events and clinical endpoints, all available information is provided to the members of the CEC, excluding the CEC adjudication for index hospitalization acute HF diagnosis. The CEC will adjudicate all hospitalizations, deaths, and other clinical events that occur throughout the trial (to 180 [+/- 14] days). 


\section{RESULTS}

Study enrollment ended October 15, 2016, with 1758 patients included (signed the informed consent form). Of these, 297 were excluded due to clinical or sample exclusion criteria, leaving 1461 enrolled, of which 1424 were from the United States and 37 were from Canada (Figure 2).



Figure 2. CONSORT Diagram. Of 1758 patients included (signed the informed consent form), $297(17 \%)$ were excluded due to subsequent clinical or sample exclusion criteria, leaving 1461 patients enrolled, with a blood sample available for analysis.

* Data are presented non-hierarchically; 2 patients also had sample exclusion criteria but are only counted in this box.

${ }^{\dagger} 57$ patients included in this box met the clinical criteria but did not have a baseline blood sample.

As seen in Table 4, patients were a mean of $56.4 \pm 15.7$ years old, $49.1 \%$ were female, and $40.4 \%$ were non-white race. Overall, $63.3 \%$ of patients had history of hypertension, $24.9 \%$ had prior $\mathrm{HF}$, and $25.4 \%$ had left ventricular ejection fraction $<40 \%$ at their most recent evaluation prior to study enrollment. Asthma was present in $30.1 \%$, chronic obstructive pulmonary disease in $27.5 \%$, and a history of lung cancer in $2.8 \%$. A total of $58.5 \%$ of patients reported being current or former smokers. For the purposes of the prespecified subgroup analyses, it is notable that $36.6 \%$ of patients were black, $52.5 \%$ had BMI $\geq 30$, and $24.0 \%$ had renal insufficiency (not presented). Not all cases of HF had been adjudicated at the time of publication and therefore it is not known how many subjects had HFrEF or HFpEF. 
Table 4: Baseline characteristics of enrolled patients.

\begin{tabular}{|c|c|}
\hline Characteristic & $\begin{array}{c}\text { All Patients } \\
\mathbf{N}=1461\end{array}$ \\
\hline \multicolumn{2}{|l|}{ Demographics } \\
\hline Age (years) $($ Mean $\pm \mathrm{SD}(\mathrm{N}))$ & $56.4 \pm 15.7(1461)$ \\
\hline Female Sex & $49.1 \%(718 / 1461)$ \\
\hline Hispanic or Latino & $13.6 \%(191 / 1406)$ \\
\hline Non-White Race & $40.4 \%(579 / 1432)$ \\
\hline \multicolumn{2}{|l|}{ Medical History } \\
\hline Diabetes Mellitus & $28.9 \%(420 / 1454)$ \\
\hline Hypertension & $63.3 \%(921 / 1455)$ \\
\hline Heart Failure & $24.9 \%(356 / 1431)$ \\
\hline Peripheral Arterial Disease & $4.3 \%(61 / 1434)$ \\
\hline Implantable Cardioverter-Defibrillator & $5.9 \%(86 / 1452)$ \\
\hline Cardiac Resynchronization Therapy & $1.7 \%(24 / 1442)$ \\
\hline Coronary Artery Bypass Graft & $6.6 \%(96 / 1451)$ \\
\hline Prior Coronary Artery Disease & $21.2 \%(307 / 1445)$ \\
\hline Previous Myocardial Infarction & $13.2 \%(188 / 1428)$ \\
\hline Previous Percutaneous Coronary Intervention & $8.9 \%(128 / 1431)$ \\
\hline Renal Insufficiency/Failure & $7.8 \%(114 / 1455)$ \\
\hline Dialysis & $0.0 \%(0 / 114)$ \\
\hline $\mathrm{eGFR}<15 \mathrm{~mL} / \mathrm{min} / 1.73 \mathrm{~m}^{2}$ & $0.0 \%(0 / 103)$ \\
\hline LVEF $<40 \%$ at Most Recent Evaluation Prior to Enrollment & $25.4 \%(103 / 405)$ \\
\hline Atrial Fibrillation & $14.9 \%(216 / 1453)$ \\
\hline Significant Mitral Valve Disease & $4.2 \%(57 / 1372)$ \\
\hline Significant Aortic Valve Disease & $2.3 \%(31 / 1338)$ \\
\hline Asthma & $30.1 \%(437 / 1450)$ \\
\hline Chronic Obstructive Pulmonary Disease & $27.5 \%(399 / 1449)$ \\
\hline History of Lung Cancer & $2.8 \%(40 / 1454)$ \\
\hline \multicolumn{2}{|l|}{ Alcohol History } \\
\hline Never & $36.6 \%(514 / 1404)$ \\
\hline Former & $16.4 \%(230 / 1404)$ \\
\hline Current & $47.0 \%(660 / 1404)$ \\
\hline \multicolumn{2}{|l|}{ Tobacco History } \\
\hline Never & $41.5 \%(591 / 1423)$ \\
\hline Former & $36.7 \%(522 / 1423)$ \\
\hline Current & $21.8 \%(310 / 1423)$ \\
\hline \multicolumn{2}{|l|}{ Cocaine History } \\
\hline Never & $89.0 \%(1227 / 1379)$ \\
\hline Former & $10.4 \%(144 / 1379)$ \\
\hline Current & $0.6 \%(8 / 1379)$ \\
\hline
\end{tabular}

Abbreviations: eGFR, estimated glomerular filtration rate; LVEF: Left ventricular ejection fraction; SD, standard deviation.

Available demographic data for patients who were excluded from the study due to either clinical or sample criteria are presented in Appendix Table 3. 


\section{DISCUSSION}

We describe the design and rationale of a large prospective multicenter, international trial primarily focused on NT-proBNP testing in ED patients presenting with acute dyspnea. In our study, performed in 19 North American institutions, we enrolled a population of patients representative of a contemporary cohort of patients presenting with acute dyspnea in whom natriuretic peptide testing would be contemplated. The central goal of this trial is to determine the most useful diagnostic cut-offs for this biomarker for the diagnosis of acute HF in a contemporary cohort of patients presenting with acute dyspnea. Additionally, this will be one of the first studies prospectively examining the role of in-hospital NT-proBNP monitoring for predicting prognosis after hospital-based treatment for acute HF.

To aid in early diagnosis of patients with acute dyspnea in the ED, readily available, accurate, and objective tools to support clinical judgment are needed.(26, 27) Early and correct diagnosis is essential, as delayed treatment for acute HF is associated with increased mortality.(28) Improvement in patient care after HF hospitalization is a major centerpiece of current efforts to control cost (29); accurate and rapid diagnosis of HF after admission to the emergency department would be expected to have a cascade effect on both the patient and the health care system, translating into prompt and proper treatment with subsequent reduction of the length of hospital stay and improvement in patient outcomes. Prior studies from $\operatorname{PRIDE}(30,31)$ and the Canadian based Improved Management of Patients with Congestive Heart Failure (IMPROVE$\mathrm{CHF}$ ) study(6) suggest that prompt, accurate diagnosis would reduce indecision, potentially improve outcomes, and lead to reduction in healthcare expenditures. The validation of the ICON diagnostic cutoffs in a contemporary cohort may thus aid in enhancing diagnosis of acute HF in the emergency department.

In addition to its value in diagnosis, NT-proBNP concentrations are associated with HF severity and are guideline supported for predicting short- to intermediate-term risk for adverse outcomes, such as death or repeat hospitalization. As shown by the first ICON investigators, NT-proBNP concentrations $>5180 \mathrm{pg} / \mathrm{mL}$ were associated with an adjusted odds ratio of $5.20(95 \%$ confidence intervals $[\mathrm{CI}]=2.20-8.10, P<.001$ ) for death by 76 days. (3) Longer term follow-up of the PRIDE study demonstrated similar prognostic value of the baseline NT-proBNP measurement through four years.(18) More recent data have suggested value of serial measurement of NT-proBNP to better assess risk. Whereas a baseline measurement of NTproBNP is useful for prognosis, subsequent re-measurement of the peptide after treatment for acute HF is of even greater predictive importance.(19-21) Although not yet supported by largescale prospective data, retrospective research indicates that two factors appear to be independently predictive of event-free survival after hospitalization for AHF: significant reduction of NT-proBNP concentration $(\geq 30 \%)$ and lower absolute NT-proBNP values at discharge.(20) The ICON-RELOADED study will prospectively assess the importance of inhospital change in NT-proBNP as a prognostic indicator of short-term hazard. 
The ability to determine disease severity and subsequently tailor therapeutic response has the potential to maximize proper care, minimize resource use, and improve healthcare outcomes. For example, results from in-hospital NT-proBNP testing could be incorporated into each of the three strategies proposed by Dunbar-Yaffe et al. to reduce readmissions for HF: (1) identify patients at high risk of readmission prior to their index hospital discharge; (2) institute remote ambulatory monitoring strategies to identify early warning signs before acute decompensation takes place, and (3) employ strategies in the emergency department to identify low-risk patients who may not need hospital readmission.(32) Of particular importance in the current health care environment in the United States is the goal of reducing 30-day hospital readmission rates for $\operatorname{HF}(29,33)$, not only to improve patient outcomes, but also to mitigate the financial penalties associated with excess readmission rates during the first 30 days after discharge.(34)

A few limitations should be considered with the eventual interpretation of this study's findings. The applicability of data generated from this North American cohort should be considered when applying the results in venues outside of the United States and Canada. Additionally, a relatively high percentage of samples (13\%) were excluded from the analysis due to various sample exclusion criteria, possibly omitting eligible subjects. However given the central goal of this trial was focused on assay validation, such exclusions are mandated. Although not tested for significance, in comparison with the original ICON study cohort,(26) the patients in the present study were numerically younger (mean 56.4 vs. 68.3 years old), less likely to have prior heart failure $(24.9 \%$ vs. $34 \%)$, prior MI $(13.2 \%$ vs. $25 \%)$, or prior coronary artery disease $(21.2 \%$ vs. $40 \%)$; and more likely to have hypertension $(63.3 \%$ vs. $53 \%)$. Females comprised about $49 \%$ of each of the studies' patient populations. As well, though results of local natriuretic peptide testing were redacted from the CEC processes, such results could theoretically influence behaviors of clinicians during patient hospitalization and care.

\section{CONCLUSION}

The ICON-RELOADED Study will validate NT-proBNP diagnostic cutoffs in a modern multicenter cohort of patients, an important step to understanding the optimal diagnostic application of this biomarker in emergency department patients. Furthermore, the study will carefully examine the role of in-hospital NT-proBNP monitoring, which may provide insights to better manage patients following hospitalization for acute HF. More accurate and timely diagnosis combined with more precise management of the HF patient may improve outcomes, in part due to better management of higher risk patients, while simultaneously reducing the burden of healthcare expenditures. 


\section{HIGHLIGHTS}

- NT-proBNP facilitates diagnosis, prognosis, and treatment of acute heart failure

- Change in patient demographics require updated diagnostic NT-proBNP cutoffs

- ICON-RELOADED aims to determine diagnostic NT-proBNP cutoffs in a sample of 1461 patients

- Prognostic value of in-hospital change in NT-proBNP will be assessed

\section{CLINICAL PERSPECTIVES:}

More accurate diagnosis of acute HF can lead to more efficient triage, more accurate therapeutic focus, reduced hospital length of stay, reduced medical expenditures, reduced disease complications, and improved clinical outcomes. In a contemporary cohort of patients presenting to the Emergency Department, the ICON-RELOADED Study will validate NT-proBNP thresholds of $450 / 900 / 1800 \mathrm{pg} / \mathrm{mL}$ for age categories of $<50 / 50-75 / \geq 75$ years for diagnosis of acute HF in a modern cohort of patients who present to the ED with acute dyspnea. Additionally, better understanding of the use of NT-proBNP for disease prognosis in acute HF may be associated with similar positive clinical implications.

\section{ACKNOWLEDGMENTS:}

Sponsored by Roche Diagnostics Inc. Dr. Gaggin is supported in part by Clark Fund for Cardiac Research Innovation. Dr. Januzzi is supported in part by the Hutter Family Professorship. Joanna Suomi, MSc, assisted with the editing and formatting of this manuscript. She is employed by the Baim Institute for Clinical Research and was compensated for her contributions. 


\section{REFERENCES:}

1. Januzzi JL, Jr., Rehman SU, Mohammed AA, Bhardwaj A, Barajas L, Barajas J, et al. Use of aminoterminal pro-B-type natriuretic peptide to guide outpatient therapy of patients with chronic left ventricular systolic dysfunction. J Am Coll Cardiol. 2011;58(18):1881-9.

2. Januzzi JL, Jr., Camargo CA, Anwaruddin S, Baggish AL, Chen AA, Krauser DG, et al. The Nterminal Pro-BNP investigation of dyspnea in the emergency department (PRIDE) study. Am J Cardiol. 2005;95(8):948-54.

3. Chen AA, Wood MJ, Krauser DG, Baggish AL, Tung R, Anwaruddin S, et al. NT-proBNP levels, echocardiographic findings, and outcomes in breathless patients: results from the ProBNP Investigation of Dyspnoea in the Emergency Department (PRIDE) echocardiographic substudy. Eur Heart J. 2006;27(7):839-45.

4. Maisel AS, Krishnaswamy P, Nowak RM, McCord J, Hollander JE, Duc P, et al. Rapid measurement of B-type natriuretic peptide in the emergency diagnosis of heart failure. $\mathrm{N} \mathrm{Engl} \mathrm{J}$ Med. 2002;347(3):161-7.

5. Meisel SR, Januzzi JL, Medvedovski M, Sharist M, Shochat M, Ashkar J, et al. Pre-admission NTproBNP improves diagnostic yield and risk stratification - the NT-proBNP for EValuation of dyspnoeic patients in the Emergency Room and hospital (BNP4EVER) study. Eur Heart J Acute Cardiovasc Care. 2012;1(2):99-108.

6. Moe GW, Howlett J, Januzzi JL, Zowall H. N-terminal pro-B-type natriuretic peptide testing improves the management of patients with suspected acute heart failure: primary results of the Canadian prospective randomized multicenter IMPROVE-CHF study. Circulation. 2007;115(24):3103-10.

7. Yancy CW, Jessup M, Bozkurt B, Butler J, Casey DE, Jr., Drazner MH, et al. 2013 ACCF/AHA guideline for the management of heart failure: a report of the American College of Cardiology Foundation/American Heart Association Task Force on Practice Guidelines. J Am Coll Cardiol. 2013;62(16):e147-239.

8. Wong CY, Chaudhry SI, Desai MM, Krumholz HM. Trends in comorbidity, disability, and polypharmacy in heart failure. Am J Med. 2011;124(2):136-43.

9. Baggish AL, van Kimmenade RR, Januzzi JL, Jr. The differential diagnosis of an elevated aminoterminal pro-B-type natriuretic peptide level. Am J Cardiol. 2008;101(3A):43-8.

10. Sharma K, Kass DA. Heart failure with preserved ejection fraction: mechanisms, clinical features, and therapies. Circ Res. 2014;115(1):79-96.

11. Owan TE, Hodge DO, Herges RM, Jacobsen SJ, Roger VL, Redfield MM. Trends in prevalence and outcome of heart failure with preserved ejection fraction. N Engl J Med. 2006;355(3):251-9.

12. Krauser DG, Lloyd-Jones DM, Chae CU, Cameron R, Anwaruddin S, Baggish AL, et al. Effect of body mass index on natriuretic peptide levels in patients with acute congestive heart failure: $a$ ProBNP Investigation of Dyspnea in the Emergency Department (PRIDE) substudy. Am Heart J. 2005;149(4):744-50.

13. Bayes-Genis A, Lloyd-Jones DM, van Kimmenade RR, Lainchbury JG, Richards AM, OrdonezLlanos J, et al. Effect of body mass index on diagnostic and prognostic usefulness of aminoterminal pro-brain natriuretic peptide in patients with acute dyspnea. Arch Intern Med. 2007;167(4):400-7.

14. Januzzi JL, van Kimmenade R, Lainchbury J, Bayes-Genis A, Ordonez-Llanos J, Santalo-Bel M, et al. NT-proBNP testing for diagnosis and short-term prognosis in acute destabilized heart failure: an international pooled analysis of 1256 patients: the International Collaborative of NT-proBNP Study. Eur Heart J. 2006;27(3):330-7. 
15. Baggish AL, van Kimmenade RR, Januzzi JL, Jr. Amino-terminal pro-B-type natriuretic peptide testing and prognosis in patients with acute dyspnea, including those with acute heart failure. Am J Cardiol. 2008;101(3A):49-55.

16. Kim HN, Januzzi JL, Jr. Natriuretic peptide testing in heart failure. Circulation. 2011;123(18):2015-9.

17. Januzzi JL, Jr., Sakhuja R, O'Donoghue M, Baggish AL, Anwaruddin S, Chae CU, et al. Utility of amino-terminal pro-brain natriuretic peptide testing for prediction of 1-year mortality in patients with dyspnea treated in the emergency department. Arch Intern Med. 2006;166(3):315-20.

18. Januzzi JL, Jr., Rehman S, Mueller T, van Kimmenade RR, Lloyd-Jones DM. Importance of biomarkers for long-term mortality prediction in acutely dyspneic patients. Clin Chem. 2010;56(12):1814-21.

19. Bettencourt P, Azevedo A, Pimenta J, Frioes F, Ferreira S, Ferreira A. N-terminal-pro-brain natriuretic peptide predicts outcome after hospital discharge in heart failure patients. Circulation. 2004;110(15):2168-74.

20. Salah K, Kok WE, Eurlings LW, Bettencourt P, Pimenta JM, Metra M, et al. A novel discharge risk model for patients hospitalised for acute decompensated heart failure incorporating $\mathrm{N}$-terminal pro-B-type natriuretic peptide levels: a European coLlaboration on Acute decompeNsated Heart Failure: ELAN-HF Score. Heart. 2013;100(2):115-25.

21. Cohen-Solal A, Logeart D, Huang B, Cai D, Nieminen MS, Mebazaa A. Lowered B-type natriuretic peptide in response to levosimendan or dobutamine treatment is associated with improved survival in patients with severe acutely decompensated heart failure. J Am Coll Cardiol. 2009;53(25):2343-8.

22. Salah K, Kok WE, Eurlings LW, Bettencourt P, Pimenta JM, Metra M, et al. A novel discharge risk model for patients hospitalised for acute decompensated heart failure incorporating N-terminal pro-B-type natriuretic peptide levels: a European coLlaboration on Acute decompeNsated Heart Failure: ELAN-HF Score. Heart. 2014;100(2):115-25.

23. Carubelli V, Lombardi C, Lazzarini V, Bonadei I, Castrini Al, Gorga E, et al. N-terminal pro-B-type natriuretic peptide-guided therapy in patients hospitalized for acute heart failure. J Cardiovasc Med (Hagerstown). 2016;17(11):828-39.

24. Mercaldo ND, Lau KF, Zhou XH. Confidence intervals for predictive values with an emphasis to case-control studies. Stat Med. 2007;26(10):2170-83.

25. Jeffrey H. Theory of probability (3rd Edition). Oxford, U.K.: Oxford University Press; 1961.

26. Collins SP, Lindsell CJ, Peacock WF, Eckert DC, Askew J, Storrow AB. Clinical characteristics of emergency department heart failure patients initially diagnosed as non-heart failure. BMC Emerg Med. 2006;6:11.

27. Weintraub NL, Collins SP, Pang PS, Levy PD, Anderson AS, Arslanian-Engoren C, et al. Acute heart failure syndromes: emergency department presentation, treatment, and disposition: current approaches and future aims: a scientific statement from the American Heart Association. Circulation. 2010;122(19):1975-96.

28. Peacock WF, Emerman C, Costanzo MR, Diercks DB, Lopatin M, Fonarow GC. Early vasoactive drugs improve heart failure outcomes. Congest Heart Fail. 2009;15(6):256-64.

29. Desai AS, Stevenson LW. Rehospitalization for heart failure: predict or prevent? Circulation. 2012;126(4):501-6.

30. Green SM, Martinez-Rumayor A, Gregory SA, Baggish AL, O'Donoghue ML, Green JA, et al. Clinical uncertainty, diagnostic accuracy, and outcomes in emergency department patients presenting with dyspnea. Arch Intern Med. 2008;168(7):741-8. 
31. Siebert U, Januzzi JL, Jr., Beinfeld MT, Cameron R, Gazelle GS. Cost-effectiveness of using Nterminal pro-brain natriuretic peptide to guide the diagnostic assessment and management of dyspneic patients in the emergency department. Am J Cardiol. 2006;98(6):800-5.

32. Dunbar-Yaffe R, Stitt A, Lee JJ, Mohamed S, Lee DS. Assessing Risk and Preventing 30-Day Readmissions in Decompensated Heart Failure: Opportunity to Intervene? Curr Heart Fail Rep. 2015;12(5):309-17.

33. Gheorghiade M, Vaduganathan M, Fonarow GC, Bonow RO. Rehospitalization for heart failure: problems and perspectives. J Am Coll Cardiol. 2013;61(4):391-403.

34. Services CfMM 2016;Pageshttps://www.cms.gov/medicare/medicare-fee-for-servicepayment/acuteinpatientpps/readmissions-reduction-program.html on 12/08/2016 2016. 


\section{APPENDIX}

Clinical endpoint committee charter definitions for adjudication of events. Definitions are based on regulatory guidance ${ }^{1}$ or clinical practice guidelines.

\section{ACUTE HEART FAILURE}

Clinical manifestations of heart failure:

a) New or worsening symptoms of heart failure (at least 1 of the following):

- Dyspnea

- Orthopnea

- Paroxysmal nocturnal dyspnea

- Increased fatigue or worsening exercise tolerance

- Worsening swelling of the legs

- Gastrointestinal distress related to congestion/low output

AND

b) New or worsening signs of heart failure (at least 2 of the following):

- Pulmonary edema

- Pulmonary basilar crackles

- Jugular venous distension / elevated jugular venous pressure / positive hepatojugular reflux

- Peripheral edema

- Rapid weight gain

- New or worsening third heart sound or gallop rhythm

- Increased abdominal distension or ascites

- Hepatomegaly (not related to liver disease)

- Radiological evidence of worsening heart failure

- Changes in biomarker (e.g., B-type natriuretic peptide or amino-terminal pro-B type natriuretic peptide) above local reference limits

- Invasive or non-invasive tests showing elevated cardiac feeling pressures or low cardiac output

AND

c) Additional/increased therapy (at least 1 of the following):

- Initiation of oral diuretic, intravenous diuretic, inotrope, or vasodilator therapy

- Uptitration of oral diuretic, intravenous therapy (if already on therapy)

- Initiation of mechanical or surgical intervention (mechanical circulatory support, heart transplantation or ventricular pacing to improve cardiac function), or the use

\footnotetext{
${ }^{1}$ Hicks KA, Tcheng JE, Bozkurt B, et al. 2014 ACC/AHA Key Data Elements and Definitions for Cardiovascular Endpoint Events in Clinical Trials. Circulation. 2015;132(4):302-61.
} 
of ultrafiltration, hemofiltration, or dialysis that is specifically directed at treatment of heart failure

\section{ACUTE DYSPNEA}

A subjective feeling of shortness of breath, difficult or labored breathing, arising or worsening over the course of no longer than several days.

\section{DEATH}

All deaths are considered cardiac unless an unequivocal non-cardiac cause can be established. Specifically, any unexpected death even in patients with coexisting potentially fatal non-cardiac disease (e.g., cancer, infection) should be classified as cardiac.

- Cardiac death

Any death due to proximate cardiac cause (e.g., MI, low-output failure, fatal arrhythmia), unwitnessed death and death of unknown cause, and all procedure-related deaths, including those related to concomitant treatment, will be classified as cardiac death.

- Cardiac death due to heart failure

- New or worsening signs and/or symptoms of heart failure include any of the signs and symptoms as detailed above for ADHF

- Cardiac death due to myocardial infarction

- New or worsening signs and/or symptoms of myocardial infarction leading to death within 30 days

- Sudden cardiac death or primary arrhythmia: refers to death that occurs unexpectedly in a previously stable patient and includes the following deaths:

- Witnessed and instantaneous without new or worsening symptoms

- Witnessed within 60 minutes of the onset of new or worsening cardiac symptoms

- Witnessed and attributed to an identified arrhythmia (e.g., captured on an electrocardiographic (ECG) recording or witnessed on a monitor by either a medic or paramedic)

- Subjects unsuccessfully resuscitated from cardiac arrest or successfully resuscitated from cardiac arrest but who die within 24 hours without identification of a non-cardiac etiology

○ Other cardiac death

- Cardiac death not meeting definitions of sudden cardiac death or death due to heart failure

- Vascular death

Death caused by non-coronary vascular causes, such as cerebrovascular disease, pulmonary embolism, ruptured aortic aneurysm, dissecting aneurysm, or other vascular diseases.

- Non-cardiovascular death 
Any death not covered by the above definitions, such as death caused by infection, malignancy, sepsis, pulmonary causes, accident, suicide, or trauma.

\section{HEART FAILURE HOSPITALIZATION}

Unplanned presentation to an acute care facility for an exacerbation of heart failure requiring an overnight stay (change in calendar day), due to signs and symptoms compatible with acute HF as defined above. 
Appendix Table 1. Elecsys ${ }^{\circledR}$ Description

\begin{tabular}{|l|l|l|}
\hline Topic & Elecsys proBNP II & Elecsys proBNP II STAT \\
\hline Test Principle & $\begin{array}{l}\text { The Elecsys proBNP II Assay } \\
\text { components are a two-step sandwich } \\
\text { immunoassay with streptavidin } \\
\text { microparticles and } \\
\text { electrochemiluminescent detection. } \\
\text { The total duration of the test system is } \\
\text { 18 minutes. }\end{array}$ & $\begin{array}{l}\text { The Elecsys proBNP II STAT Assay } \\
\text { components are a two-step sandwich } \\
\text { immunoassay with streptavidin } \\
\text { microparticles and } \\
\text { electrochemiluminescent detection. } \\
\text { The total duration of the test system } \\
\text { is 9 minutes. }\end{array}$ \\
\hline Incubation & $\begin{array}{l}\text { 1st incubation: Antigen in the sample } \\
\text { (15 } \mu \text { L), a biotinylated monoclonal NT- } \\
\text { proBNP-specific antibody, and a } \\
\text { monoclonal NT-proBNP-specific } \\
\text { antibody labeled with a ruthenium } \\
\text { complex form a sandwich complex. } \\
\text { 2nd incubation: After addition of } \\
\text { streptavidin-coated microparticles, the } \\
\text { complex becomes bound to the solid } \\
\text { phase via interaction of biotin and } \\
\text { streptavidin. }\end{array}$ & $\begin{array}{l}\text { During a nine (9) minute incubation, } \\
\text { antigen in the sample (15 } \mu \text { L), a } \\
\text { biotinylated monoclonal NT- } \\
\text { proBNP-specific antibody, a } \\
\text { monoclonal NT-proBNP-specific } \\
\text { antibody labeled with a ruthenium } \\
\text { complex and streptavidin-coated } \\
\text { microparticles react to form a } \\
\text { sandwich complex, which is bound to } \\
\text { the solid phase. }\end{array}$ \\
\hline
\end{tabular}


Appendix Table 2. Site and Investigator List

\begin{tabular}{|l|c|c|}
\hline Site Name & Investigator & Location \\
\hline Baylor College of Medicine & Peacock, Frank & Houston, TX, USA \\
\hline Beth Israel Deaconess Medical Center & Shapiro, Nathan & Boston, MA, USA \\
\hline Henry Ford Hospital & Nowak, Richard & Detroit, MI, USA \\
\hline Jewish General Hospital & Chen-Tournoux, Annabel & Montreal, QC, Canada \\
\hline Loma Linda University Health & Walters, Elizabeth & Loma Linda, CA, USA \\
\hline Massachusetts General Hospital & Nagurney, John & Boston, MA, USA \\
\hline Methodist Hospital & Pang, Peter & Indianapolis, IN, USA \\
\hline Stony Brook University Medical Center & Singer, Adam & Stony Brook, NY, USA \\
\hline Thomas Jefferson University & Hollander, Judd & Philadelphia, PA, USA \\
\hline Toronto General Hospital & Chang, Anna Marie & Toronto, ON, Canada \\
\hline Torrance Memorial Medical Center & Ross, Heather & Torrance, CA, USA \\
\hline University of Kansas Hospital & Lurie, Mark & Kansas City, KS, USA \\
\hline University of Maryland Medical Center & Cannon, Chad & Baltimore, MD, USA \\
\hline University of Southern California & Christenson, Robert & Los Angeles, CA, USA \\
\hline $\begin{array}{l}\text { University of Texas Health Science Center at San } \\
\text { Antonio }\end{array}$ & DeLorenzo, Robert & San Antonio, TX, USA \\
\hline University of Texas Southwestern Medical Center & Blomkalns, Andra & Dallas, TX, USA \\
\hline University of Washington & Cheng, Richard & Seattle, WA, USA \\
\hline Wake Forest Health Sciences & Hiestand, Brian & Winston-Salem, NC, \\
\hline Wayne State University & Levy, Phillip & Detroit, MI, USA \\
\hline
\end{tabular}


Appendix Table 3. Characteristics of patients whose samples were excluded from analyses due to clinical or sample exclusion criteria.

$\begin{array}{ll}\text { Characteristic } & \text { N=297 Subjects }\end{array}$

Demographics

Age (years) (Mean \pm SD $(\mathrm{N}))$

$55.1 \pm 15.5(297)$

Female Sex

$52.2 \%(155 / 297)$

Hispanic or Latino

$17.2 \%(50 / 290)$

Nonwhite Race

$48.6 \%(140 / 288)$

Abbreviations: eGFR, estimated glomerular filtration rate; LVEF: Left ventricular ejection fraction; SD, standard deviation 